\title{
Assessment of kaolin resources using electrical resisitivity method in part of Ekiti state southwest Nigeria
}

\author{
Akinniyi Akinsunmade ${ }^{1, *}$, Sylwia Tomecka-Suchoń ${ }^{1}$, and Pawet Pysz ${ }^{1}$ \\ ${ }^{1}$ Faculty of Geology, Geophysics and Environmental Protection, AGH University of Science and \\ Technology, Krakow, Poland
}

\begin{abstract}
Consistent building of mineral database is very crucial to ascertaining the natural resources potential of a nation which may be valuable towards its development. Essentially, the study aimed at establishing the spatial extent and average thickness occurrence of the kaolin deposit in part of Ikere-ekiti, south western Nigeria using geophysical method. Seventy seven VES measurements and two parametric soundings were made. The data were processed and interpreted using IPIwin - a forward modelling software. The evaluated geoelectric parameers were used for the generation of maps(2D and 3D) depicting the mineral occurrence variation. Three-five subsurface layers were depicted within the study area with layer resistivity ranging from 1 to $7250 \mathrm{ohm}-$ meters and layer thickness that range from 0.2 to 48 meters. Layers with a resistivity range of $1-150 \mathrm{ohm}$ meters have been identified as the kaolin layers. Average thickness of the kaolin layer range from 0.8 to 46 meters. Overburden thickness were found to range from 0.3 to 44 meters. The lateral extents of the kaolin occurrence in the study site have been delineated by electrical geophysical sounding method. The obtained information may serve as database for detail exploration and exploitaion programme towards harnessing the reosurces.
\end{abstract}

Keywords: geoelectric parameters, kaolin, geophysical investigation, mineral resources

\section{Introduction}

The dwindling global oil price few years ago resulted in depletion of foreign exchange earnings, loss of job, inflation and even recession in Nigeria. In order to circumvent these negative influences on the economy, the Nigerian government has been advocating for diversification of the economy from oil base to non-oil base. Solid mineral sector has been

\footnotetext{
* Corresponding author: akinsunmade@agh.edu.pl
} 
identified as one of the sectors that have the potential to generate revenue for the government, create employment for the teaming youth, attract foreign direct investment, provide raw material for local industries and help reduce Nigeria dependence on importation of raw materials that are locally available.

Residual deposits (kaolin inclusive) are widely distributed on the Precambrian Basement of Nigeria. This is due to the location of Nigeria within the tropics where the climate is characterized by high temperature, high rainfall and high humidity which may be favorable for the formation of residual minerals. Clay minerals constitute part of the residual deposits. Clays consist of essentially hydrous alumino-silicates, which normally on heating lose all their water to yield refractory clay. The main chemical components of clay are silica and alumina, with alkali, iron, calcium, zinc and magnesium ions as important accessory elements. They also contain groups of crystalline substances known as non-clay minerals such as quartz, feldspar, and mica [1]. They are utilized as raw material in brick making and ceramic production. In the construction industries, clay is used in the production of tiles, cement, and structural bricks. Refractory clays are also required in Iron and Steel industries as liner in lime kiln and furnace.

Kaolin $\left(\mathrm{Al}_{2} \mathrm{Si}_{2} \mathrm{O}_{5}(\mathrm{OH})_{4}\right)$ belongs to the group of clay minerals that contains atoms of silicon, aluminum, oxygen and hydroxyl groups as the main constituents. It also has other elements such as phosphorus, Potassium, calcium, sodium, magnesium, etc. in minutest quantities. Members of the kaolin family include dickite, nacrite, allophone, and hallosite [2].

Kaolin (with chemical formula $\mathrm{Al}_{2} \mathrm{Si}_{2} \mathrm{O}_{5}(\mathrm{OH})_{4}$ ) as a raw material has found wide applications in many industries. Kaolin is used in pottery, paint making, rubber production, paper making, as additive in powder making and as fillers in the manufacture of some pharmaceutical products. The need to look inward and save the economy from collapse due to the adverse effect of excessive importation and consumption of raw materials and products that are locally available in the country cannot be over-emphasized.

The economic viability of a kaolin deposit depends on its physical, chemical, mineralogical quality, areal and depth extent. Occurrence of Kaolin deposits are wide spread in Nigeria. Virtually every state in Nigeria has at least one known deposits of kaolin. In Anambra state, there is the Ozubulu deposit, Darazo deposit in Bauchi, Akpene- Obom deposit in Cross-River state, Kankara deposit in Kaduna state and many more in other states of the country. The three most extensively studied deposits are the Ozubulu deposits Kankara deposits and Porter deposits in Plateau state [1].

There are records of several authors in the literature on evaluation of kaolin occurrences. [3] used a statistical approach, rank-correlation, to show relationships between physical and chemical properties of the Kankara kaolinite. The geological setting of the kaolin deposits in lower Cretaceous fluvial Chaswood formation, Nova Scotia, was interpreted from high resolution seismic-reflection profiles and boreholes, and mineralogical studies on one reference borehole [4]. It has been documented by [5] the use chemical analyses, X-ray diffraction, differential thermal analysis, scanning electron microscopy and isotope analyses to model kaolinite occurrences in Southern Angola. Electrical geophysical evaluation of Kaolin in part of Ekiti state, Nigeria has been recorded by [6].

Nigeria is situated within the Pan African mobile belt and sandwiched between the West African Craton to the west, the Taureq Shield to the north and the Congo Craton to the southeast. About half of the total area of Nigeria landmass is underlain by rocks of the Precambrian age known in the country as the Basement complex [7]. The remaining half is covered by Cretaceous to Quaternary sediments and volcanic. The Western Province is approximately west of longitude $8^{\circ} \mathrm{E}$, typified by N-S to NNE-SSW trending schist belts separated from one another by migmatites, gneisses and granites [7]. 
The study area is underlain by the Older Granite and charnockitic rocks of the crystalline Basement complex of southwestern Nigeria. The Older Granite rocks include coarse grained biotite hornblende granite. The coarse grained biotite hornblende granite occurred mostly at the northern part of the study area [8]. The study was aimed at ascertain the lateral extents and average thickness of kaolin occurrence in the study location using vertical electrical sounding (VES) measurements The measurements were conducted between February and March 2017 as part of the mineral resources base evaluation by Nigerian Geological Survey Agency (NGSA).

\section{Study Location}

The mineral occurrence where the study was carried out is located northeast of Ikere-Ekiti town, south western, Nigeria (Figure 1). The area extent is defined by latitudes $7^{\circ} 29^{\prime} 59^{\prime \prime}$ and $7^{\circ} 30^{\prime} 15^{\prime \prime} \mathrm{E}$ and longitudes $05^{\circ} 14^{\prime} 35^{\prime \prime}$ and $05^{\circ} 14^{\prime} 44^{\prime \prime} \mathrm{N}$. It is approximately 70,000 square meters.

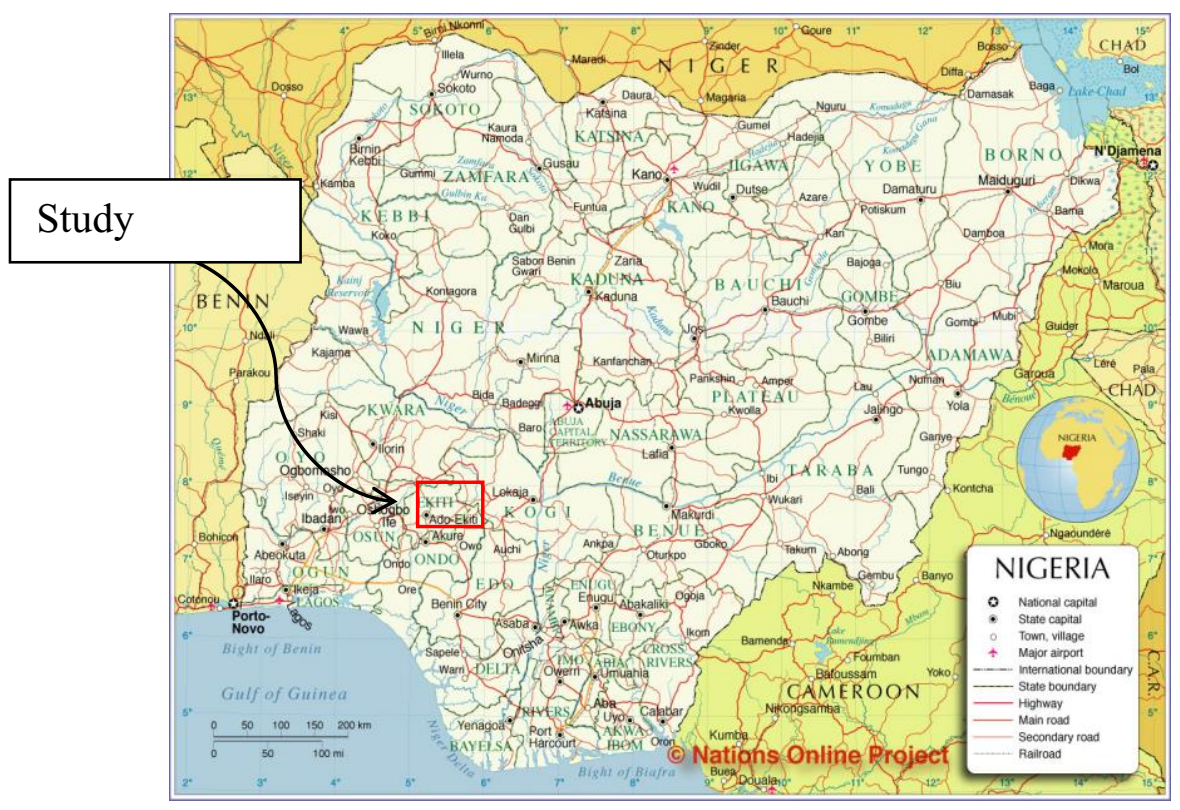

Fig. 1. Map of Nigeria with inset showing the study location. [9]

Field measurement area lies within the tropical continental climatic zone classified as $A_{w}$ by Koppen [10]. It has been recorded in literature that the climate of the study area belongs to a sub-type of the tropical continental climate known as moderate tropical continental climate, which is characterized by high annual and double maxima rainfall in July and September and a shorter dry season period of 4 to 6 months. The vegetation is characterized by thick evergreen tall trees with thick undergrowth [11].

\section{Methodology}

Schlumberger electrode array was deployed for the field data measurement. Field acquisitions were made using Scintrex Automatic Resistivity Imaging System (SARIS),manufactured by Scintrex limited, with the associated source of power (charged battery) 
which powers the current (I) injected into the earth, the resultant voltage (V) and display of the corresponding apparent resistivity ( $\rho$ a). The unit has sensitivity range of $0.1 \mathrm{~mA}$ and 0.1 $\mathrm{mV}$ for current and voltage respectively. Eleven (11) station points of 20 meters interval were established along seven (7) traverses. Current electrode separation (AB) for this study varies from $3.0 \mathrm{~m}$ to $190.0 \mathrm{~m}$ while the potential electrode separation varied from $1.0 \mathrm{~m}$ to $28.0 \mathrm{~m}$. A total of seventy seven (77) VES data were obtained. Two (2) of these data were obtained near existing hand dug pits (parametric sounding) for correlation of geoelectric parameters with subsurface sequence lithology information obtained from the logged data of the pit. The layout of the VES points is shown in Figure 2.

The field data, which is the apparent resistivity $\left(\rho_{a}\right)$ at various separations $(A B / 2)$, were obtained from the resistivity meter directly. These data were presented as VES curves by plotting the apparent resistivity $\left(\rho_{a}\right)$ against the electrode spacing $(\mathrm{AB} / 2)$ on Bi-Logarithm graph electronically using IPIwin 2 software. The best smooth curve along the data plotted was drawn for each station position. The shape of the curve is a characteristic of the subsurface layers as obtained by the VES survey.

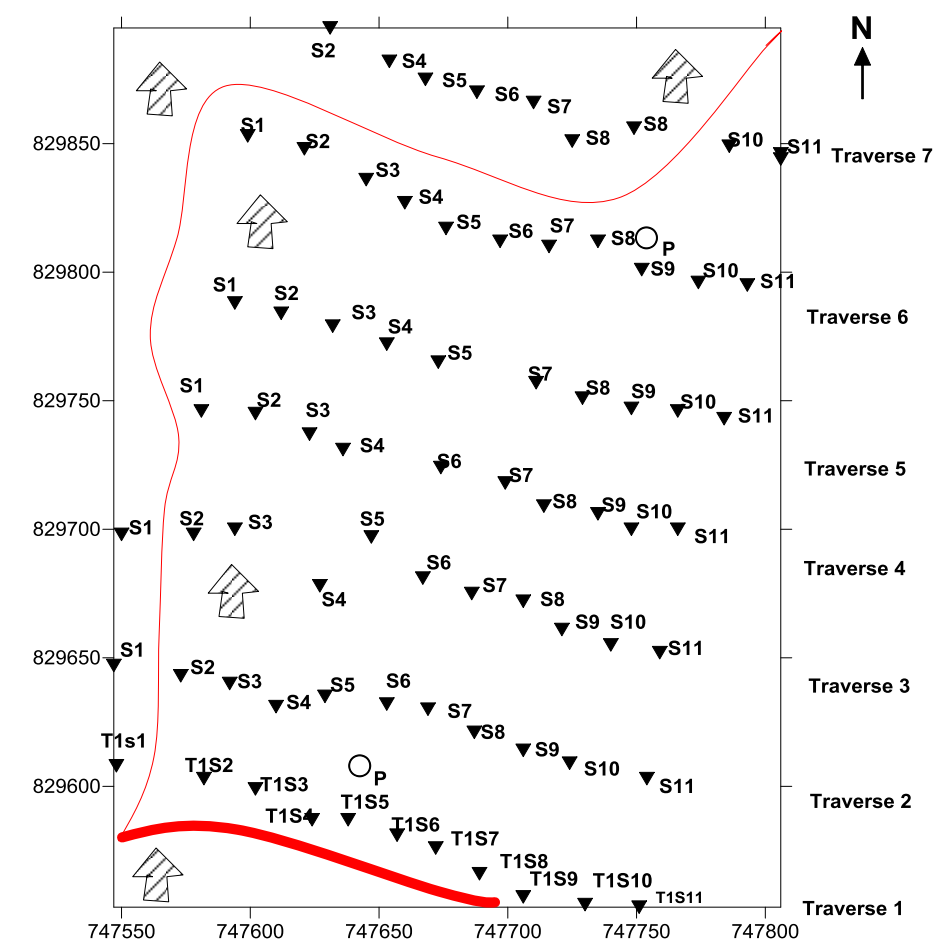

VES Data station points
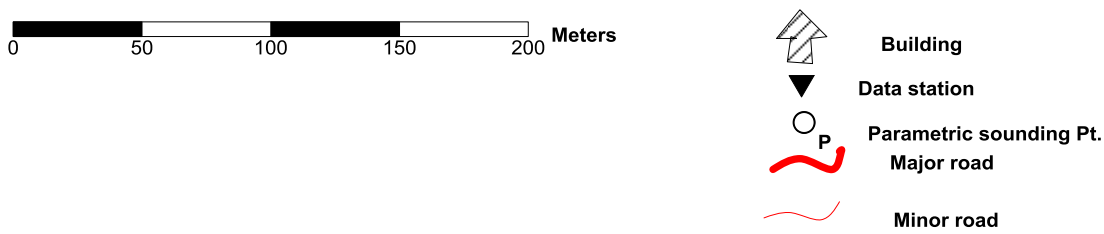

Fig. 2. Sketch of study location with data station layout. 
The VES curves were interpreted using the IPIwin 2 extension which operates on forward modeling algorithm. Minimum best fit error was maintained for optimum accuracy of interpretation. The geoelectric (layer resistivity and thickness) parameter obtained serve as the input in golden software (Surfer)-computer program for the display of the spatial variation maps generated. The parametric sounding data were interpreted and correlated with the available logged pit data in figure 6 . This aided the identification of the subsurface layers from geoelectric parameters.

\section{Results and discussion}

Interpretation of the field data has enhanced identification of 3-5 subsurface layers with corresponding thickness. Four layers sequence occupy $44.5 \%$ of the area and the three layers sequence occupy about $41 \%$. Layers resistivity range from 1 to $7250 \mathrm{ohm}$-meters and layer thickness also range from 0.2 to 48 meters. The geoelectric parameters (layer resistivity) on the columna section from depth of about 1.0 meter to 7.5 meters depth on figure 6 a seem to correlate with the same layer on the logged pit which was recorded as kaolin.

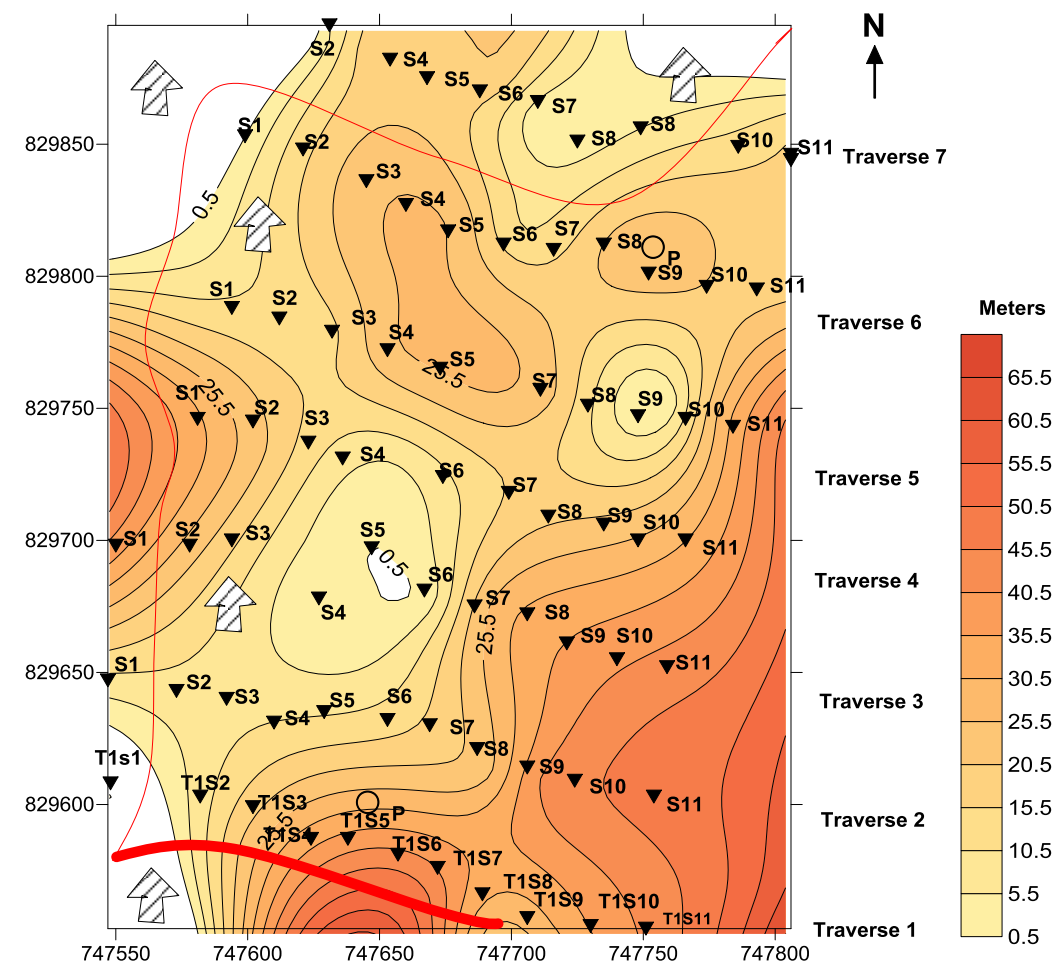

VES Data station points
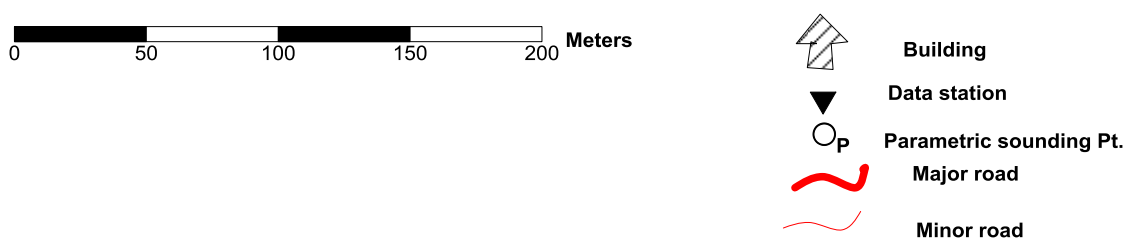

Fig. 3. Kaolin layer thickness map. 
This is based on resistivity range value of clay which is $50-150 \mathrm{ohms}$ meter [13]. It is noted that there is correlation on the plot on figure $6 \mathrm{~b}$ though there are little colour variations that seperated it to sub-layers. Layers with a resistivity in this range of value have been identified as the kaolin layers. These are found to be spatially extensive and relatively thick from the central part to the south eastern flank of the study area. A pocket of an extension of the resourses are also desernable at the western border of the site on Figures 2 and 3. Average thickness of the kaolin layer range from 0.8 to 46 meters. Overburden thickness has been found to be from 0.3 to 44 meters.

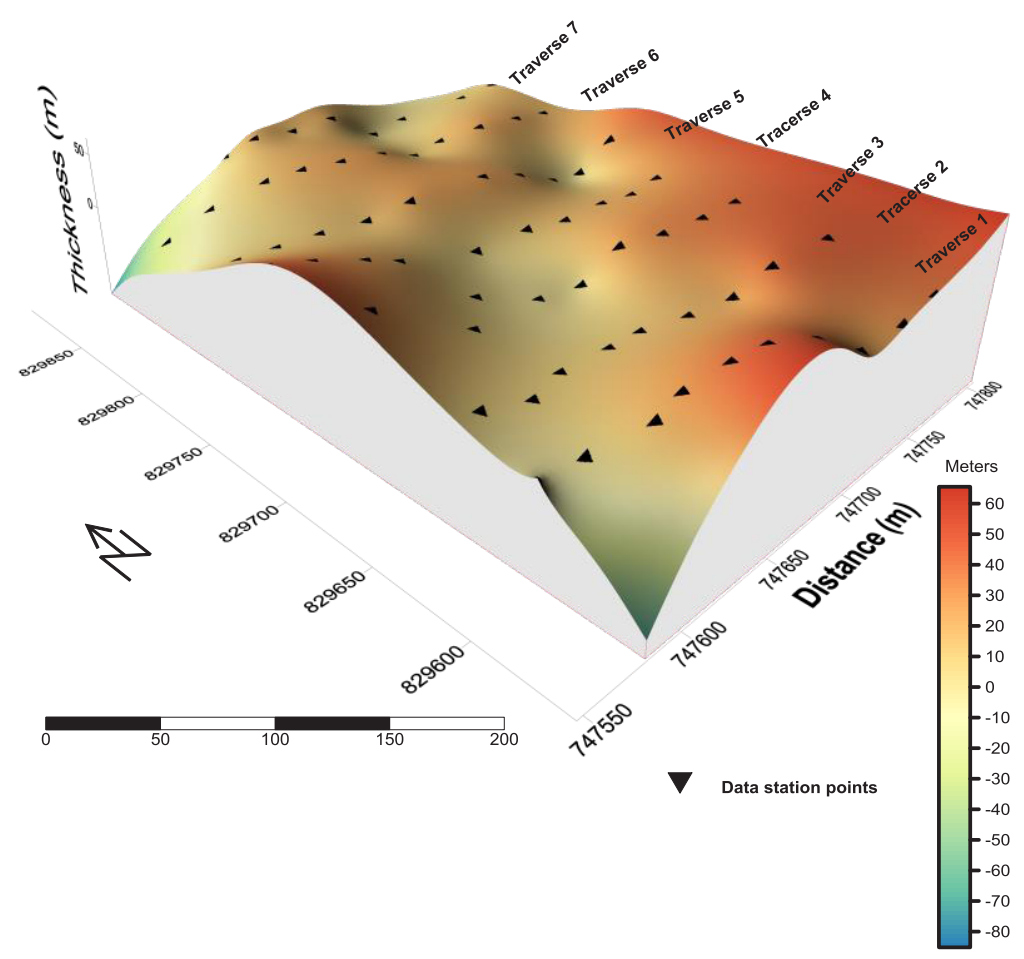

Fig. 4. 3D surface map of the Kaolin Layer thickness.

Table 1. Geoelectric parameters of the parametric sounding

\begin{tabular}{|c|c|c|c|c|c|c|c|c|c|c|c|c|}
\hline \multirow[t]{2}{*}{$\mathrm{S} / \mathrm{N}$} & \multirow{2}{*}{$\begin{array}{l}0 \\
Z \\
\infty \\
\text { In } \\
>\end{array}$} & \multirow{2}{*}{ 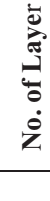 } & \multicolumn{5}{|c|}{ Layer Resistivity (Ohm Meter) } & \multicolumn{5}{|c|}{ Layer Thickness (Meter) } \\
\hline & & & 1 & 2 & 3 & 4 & 5 & 1 & 2 & 3 & 4 & 5 \\
\hline 1 & $\begin{array}{l}\text { PIT } \\
\text { Point } 1\end{array}$ & 5 & 60 & 632 & 112 & 25 & 705 & 0.6 & 0.4 & 7.4 & 35.8 & \\
\hline 2 & $\begin{array}{l}\text { PIT } \\
\text { Point 2 }\end{array}$ & 5 & 1586 & 87 & 55 & 9 & 5489 & 0.3 & 2.8 & 13.6 & 17 & \\
\hline
\end{tabular}




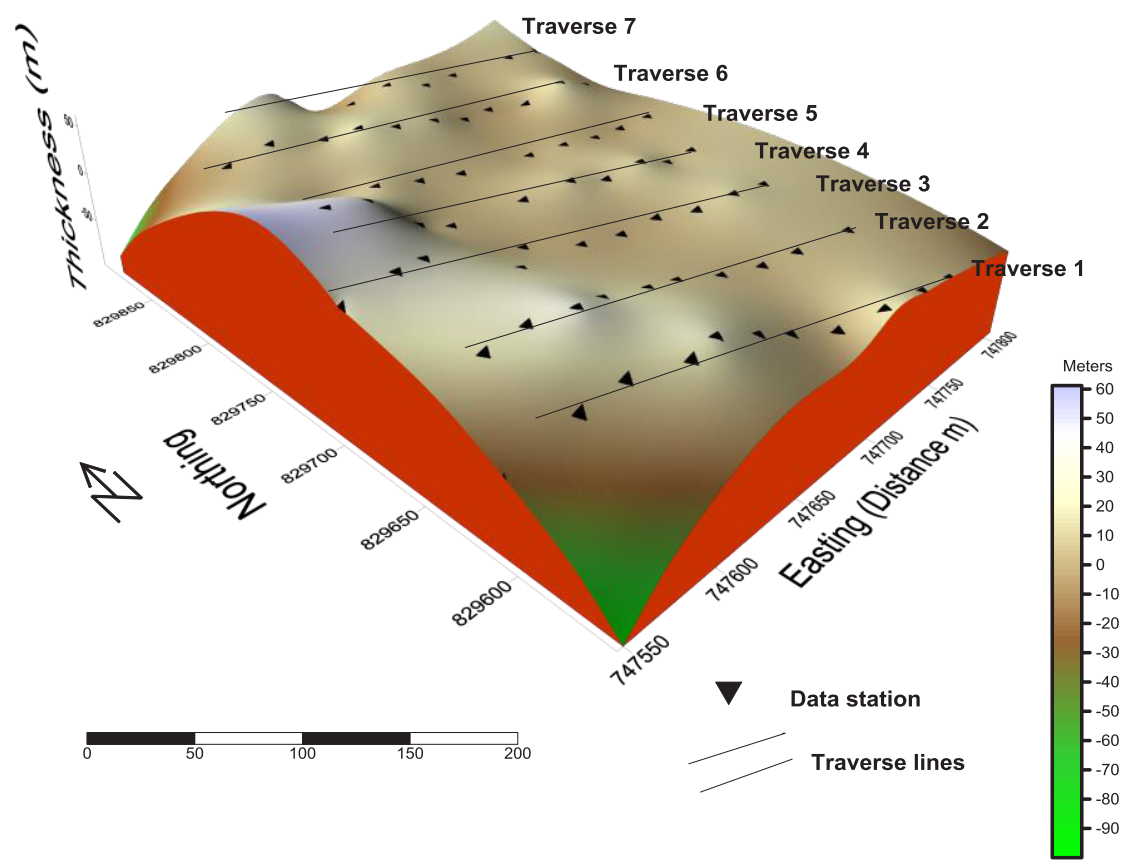

Fig 5. 3D Overburden layer thickness map.

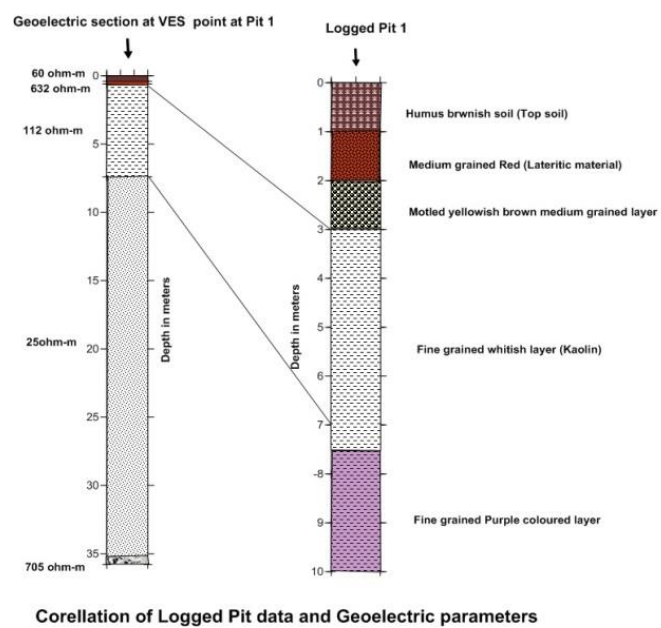

Fig. 6a. Parametric sounding data plot and Logged pit data plot 


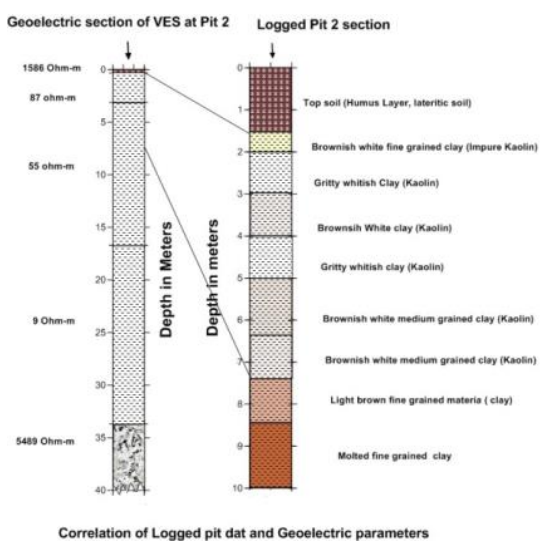

Fig. 6b. Parametric sounding data plot and Logged pit data plot

\section{Conclusions}

Analysis of electrical resistivity measurements for assessing the lateral extent and thickness of kaolin occurrence have been discussed in this paper. Interpreted field data have shown the lateral continuity of the kaolin occurrence from the central portion of the study site towards the southeastern portion. On the west flank of the study map has also a portion of the kaolin occurrence. The results have demonstrated that the method of investigation (vertical electrical sounding) can be used swiftly as part and compliment of mineral exploration methods. The study has also shown that subsurface investigations with emphasis on mineral assessment are achievable when integrated with geophysical and geological information. This type of evaluation can be precursor to detail mineral exploration stages.

The research was supported by NGSA and article was financed AGH University of Science and Technology as a Science Project no. 11.11.140.645

\section{References}

1. B.S. Badmus, O.B. Olatinsu, Int'l. Jour. of Phy. Sc. 4, 592 (2009).

2. G. W. Brindley, Min. Mag., 29, 502 (1951).

3. T.O. Odozi, S.O. Odeyemi, Appl. Clay Sc. 10, 387(1996).

4. T. Hundert, D.J.W. Piper, G. Pe-Pipe, Explor. Min. Geol., 15, 9 (2006).

5. G. Savino, M. Violo, U. Pieruccini, E.T. Da-silva, C and C Minerals, 53, 674 (2005).

6. A.K. Ogunda, O.O. Olutomilola, A. Okunade, A.O. Aladesanmi, The Int'l Jour. Of Eng. And Sc. (IJES) 4, 71 (2015).

7. I. V.Haruna, J. of Appl. Geol. and Geophy. (IOSR-JAGG) 5, 37 (2017).

8. N.G. Obaje, Geology and mineral resources of Nigeria, lecture notes in earth sciences, New York: Springer 28 (2009).

9. Federal Ministry of works, land and housing, Atlas of the Federal Republic of Nigeria, $1^{\text {st }}$ edition, 10 (1999).

10. W. Köppen, Geogr. Zeitschr. 6, 593, 657 (1900).

11. N. Iloeje, A New Geography of Nigeria. Longman Nigeria Limited 221 (2004).

12. J.M. Reynolds, An introduction to Applied and Environmental Geophysics, WileyBlackwell Scientific publications, Oxford, 291(2011). 